\title{
Synthesis, photophysical and electrochemical properties of novel carbazole- triazine based high triplet energy, solution-processable materials
}

\author{
Saliha Oner ${ }^{\mathrm{a}, \mathrm{b}}$, Murat Aydemir ${ }^{\mathrm{c}}$, Fatih Yesil ${ }^{\mathrm{a}}$, Cigdem Sahin ${ }^{\mathrm{d}}$, Canan Varlikli ${ }^{\mathrm{e}, *}$ \\ a Solar Energy Institute, Ege University, Bornova, 35100 Izmir, Turkey

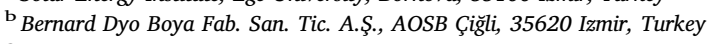 \\ ${ }^{\mathrm{c}}$ Department of Basic Sciences, Erzurum Technical University, 25070 Erzurum, Turkey \\ d Department of Chemistry, Art\&Science Faculty, Pamukkale University, Denizli, Turkey \\ e Department of Photonics, Izmir Institute of Technology, 35430 Urla-Izmir, Turkey
}

A R T I C L E I N F O

\section{Keywords:}

Bipolar materials

Charge transfer

Carbazole

Triazine

\begin{abstract}
A B S T R A C T
A series of molecules; tBuCz1SiTrz, tBuCz2SiTrz and tBuCz3SiTrz, which contain carbazole unit as hole-transporting group (donor-D) and triazine unit as electron transporting group (acceptor-A) were synthesized and characterized as high-triplet energy $(>2.9 \mathrm{eV})$, solution-processable bipolar emitting materials. The conjugation between the D-A groups was interrupted by using bulky tetraphenylsilane groups as spacer aiming to obtain large bandgap and high-triplet energy. The photophysical behaviors of the molecules were investigated by UVVis absorption, photoluminescence, phosphorescence, photoluminescence quantum yield and lifetime measurements. Solvent polarity effects were investigated on the intramolecular charge transfer (ICT) behaviour and large solvatochromic effect was observed with the increasing solvent polarity. Electrochemical properties were determined by cyclic voltammetry. All molecules showed oxidation bands arise from the carbazole groups. Reduction bands were originated from the triazine groups and the intramolecular charge transfer between D-A groups. Photophysical, electrochemical and computational characterizations addressed that tBuCz2SiTrz has the weakest ICT character, highest photoluminescence quantum yield (PLQY) and charge balance.
\end{abstract}

\section{Introduction}

In terms of organic optoelectronic research, obtaining efficient and stable blue color is still a challenge. Up to date many different blue emitting and host materials including carbazole derivatives have been reported [1-3]. High triplet energy $\left(\mathrm{E}_{\mathrm{T}}\right)$ values and high oxidative potentials make carbazole derivatives attractive as hole transport materials as well [4-8]. Recently, bipolar emitting materials those of which provide both hole and electron transporting groups in the same molecule and ensure balanced charge transfer for effective radiative recombination started to take intensive attention [6,9-12]. Several electron accepting groups such as phosphine oxide [13], diarylborane [14], benzimidazole [6] and triazine [15-18] have been attached to carbazole through continuous or interrupted $\pi$ conjugation. These bipolar materials have been presented as both bipolar hosts available to be used with blue, red or yellow-green-emitting materials and emitters by themselves. Within the electron accepting groups, triazine attracted much attention. However in most of the triazine containing bipolar material reports, high electron affinity of it could not be balanced and increasing the units of electron donor carbazoles around the triazine core resulted in bathochromic shifts mainly because of the extended $\pi$ conjugation [16,19-21]. Interrupted $\pi$ conjugation allows intramolecular charge transfer (ICT) mechanism [22,23] and may provide balanced charge transfer by preventing those shifts.

Herein, series of bipolar materials are reported by increasing the number of electron donating (D) carbazole units around the electron accepting (A) triazine. Tetraphenylsilane is used for the interruption of the $\pi$ conjugation between $\mathrm{D}$ and $\mathrm{A}$ and to ensure a high $\mathrm{E}_{\mathrm{T}}$ with the $\delta$ -Si structure and to increase the steric hindrance [24,25]. Variation of charge transfer mechanisms depending on the number of D units is reported.

\section{Experimental section}

\subsection{Materials and instruments}

All the reagents and solvents used were purchased from Aldrich and used without further purification. The solvents used for the purification steps were technical grade and distilled before using. THF was dried over $\mathrm{Na}$ /benzophenone and freshly used for the reactions. Toluene was

\footnotetext{
* Corresponding author.

E-mail address: cananvarlikli@iyte.edu.tr (C. Varlikli).
} 
dried over Na wire. ${ }^{1} \mathrm{H}$ NMR and ${ }^{13} \mathrm{C}$ NMR spectra were recorded on a Bruker spectrometer $\left({ }^{1} \mathrm{H}\right.$ at $400 \mathrm{MHz},{ }^{13} \mathrm{C}$ at $\left.100 \mathrm{MHz}\right)$ using tetramethylsilane (TMS) as an internal standard. Mass spectra were obtained using Bruker Daltonics - Autoflex III smartbeam MALDI TOF/TOF MS. UV-Vis absorption spectra were recorded by using Analytik Jena S 600 UV-Vis spectrophotometer. Photoluminescence (PL), lifetime and photoluminescence quantum yield (PLQY) studies were performed by using Edinburgh Instruments FLS920P spectrophotometer. Absolute PLQY values of the solution and films were determined with the integrating sphere attachment. Molecular geometries of molecules were optimized by using Hyperchem Package Version 8.0 computational software. Semi empirical calculations were performed using AM1 method [26,27]. Electrochemical studies were carried out with a $\mathrm{CH}$ Instrument $660 \mathrm{~B}$ Model Electrochemical Workstation by using a three-electrode electrochemical cell configuration. Glassy carbon as the working electrode, $\mathrm{Pt}$ wire as the auxiliary electrode and $\mathrm{Ag}$ wire as the reference electrode were used. Ferrocene/ferrocenium $\left(\mathrm{CP}_{2} \mathrm{Fe} / \mathrm{CP}_{2} \mathrm{Fe}^{+}\right)$redox couple was used as the internal standard and 0.1 M TBAP in DMF was used as the supporting electrolyte. Cyclic voltammograms were obtained at a scan rate of $100 \mathrm{mV} \mathrm{s}^{-1}$ and the oxidation potentials $\left(\mathrm{E}_{\mathrm{ox}}\right)$ were determined from the onsets of the oxidation peaks. Current density-Voltage curves of hole and electron only devices were obtained using a Keithley 2400 source measurement unit.

\subsection{Synthesis}

\subsubsection{Synthesis of 3,6-di-tert-butyl-9H-carbazole (1)}

Carbazole $(5.01 \mathrm{~g}, 30 \mathrm{mmol})$ and $\mathrm{AlCl}_{3}(3.99 \mathrm{~g}, 30 \mathrm{mmol})$ were weighed into a 250-mL 3-necked round-bottom flask. Dichloromethane (DCM, $100 \mathrm{~mL}$ ) was added to the flask and the solution was cooled to $0{ }^{\circ} \mathrm{C}$ with an ice-water bath. Tert-butyl chloride (t-BuCl, $66 \mathrm{mmol}$, $7.3 \mathrm{~mL})$ was dissolved in $\mathrm{CH}_{2} \mathrm{Cl}_{2}(20 \mathrm{~mL})$ and added to the flask dropwise at $0{ }^{\circ} \mathrm{C}$. The resultant solution was left to stir at room temperature (RT) overnight. $100 \mathrm{~g}$ of cold water was added to the reaction mixture and the organic phase was extracted. The water phase was washed with $\mathrm{CH}_{2} \mathrm{Cl}_{2}(50 \mathrm{~mL})$ and the organic phases were combined and dried over $\mathrm{MgSO}_{4}$. After removal of the solvent, the residue was purified by recrystallization from $\mathrm{CH}_{2} \mathrm{Cl}_{2}$ /petroleum ether mixture and pale white solid was obtained. Yield: $54 \% .{ }^{1} \mathrm{H}$ NMR $\left(\mathrm{CDCl}_{3}, 400 \mathrm{MHz}\right): \delta_{H}(\mathrm{ppm})$ $8.07(2 \mathrm{H}, \mathrm{s}, \mathrm{Ar}), 7.66(1 \mathrm{H}, \mathrm{s}, \mathrm{N}-\mathrm{H}), 7.47-7.42(2 \mathrm{H}, \mathrm{d}, J=8.4 \mathrm{~Hz}, \mathrm{Ar})$, 7.25-7.22 $(2 \mathrm{H}, \mathrm{d}, J=8.8 \mathrm{~Hz}, \mathrm{Ar}), 1.44(18 \mathrm{H}, \mathrm{s}) .{ }^{13} \mathrm{C} \mathrm{NMR}\left(\mathrm{CDCl}_{3}\right.$, $100 \mathrm{MHz}): \delta_{C}(\mathrm{ppm}) 142.49,138.29,123.76,123.56,116.40,110.30$, $34.96,32.31$.

\subsubsection{Synthesis of bis(4-bromophenyl)(diphenyl)silane (2)}

1,4-dibromobenzene ( $12 \mathrm{mmol}, 2.83 \mathrm{~g}$ ) was weighed into a $250-\mathrm{mL}$, 2 necked flask and dissolved in THF ( $50 \mathrm{~mL}$ ). The solution was cooled to $-78^{\circ} \mathrm{C}$ by using a dry ice/acetone mixture. $N$-butyllithium ( $n$-BuLi, $2.5 \mathrm{M}$ in hexane, $14.40 \mathrm{mmol}, 5.76 \mathrm{~mL}$ ) was added dropwise to the flask using a syringe and the solution was stirred at $-78^{\circ} \mathrm{C}$ for $1 \mathrm{~h}$. After that, dichloro(diphenyl)silane $(5 \mathrm{mmol}, 1.05 \mathrm{~mL}$ ) was added dropwise and the resultant solution was stirred at RT overnight. Water $(50 \mathrm{~mL})$ was added to the reaction mixture and the THF phase was extracted. The water phase was washed with $\mathrm{CH}_{2} \mathrm{Cl}_{2}(2 \times 50 \mathrm{~mL})$, and the organic phases were collected and dried over $\mathrm{MgSO}_{4}$. After the removal of the solvents, a white solid was obtained and purified by recrystallization from the DCM/EtOH mixture. Yield: $51 \% .{ }^{1} \mathrm{H} \mathrm{NMR}\left(\mathrm{CDCl}_{3}, 400 \mathrm{MHz}\right)$ : $\delta_{H}(\mathrm{ppm}) 7.60-7.52(8 \mathrm{H}, \mathrm{m}, \mathrm{Ar}), 7.47-7.35$ (10H, m, Ar). ${ }^{13} \mathrm{C} \mathrm{NMR}$ $\left(100 \mathrm{MHz}, \mathrm{CDCl}_{3}\right): \delta_{C}$ (ppm) 138.07, 136.47, 133.27, 132.93, 131.47, 130.25, 128.36, 125.23 .

\subsubsection{Synthesis of 9-\{4-[(4-bromophenyl)(diphenyl)silyl]phenyl\}-3,6-di-} tert-butyl-9H-carbazole (3)

$100 \mathrm{~mL}, 2$-necked round-bottom flask equipped with a reflux condenser was dried by using heat-gun. Bis(4-bromophenyl)(diphenyl)silane $(7.0 \mathrm{mmol}, 3.46 \mathrm{~g}), 3,6$-di-tert-butyl- $9 H$-carbazole $(5.0 \mathrm{mmol}$,
$1.40 \mathrm{~g})$, CuI ( $1.0 \mathrm{mmol}, 0.19 \mathrm{~g})$ and $\mathrm{K}_{3} \mathrm{PO}_{4}(10.0 \mathrm{mmol}, 2.12 \mathrm{~g})$ were weighed and transferred into the reaction flask. Three times vacum gas (Ar) was applied to remove the $\mathrm{O}_{2}$ from the reaction flask. 1,4dioxane $(25 \mathrm{~mL})$ was added to the reaction flask and stirred for about $10 \mathrm{~min}$. After that, trans-1,2-diaminocyclohexane $(2 \mathrm{mmol}, 0.24 \mathrm{~mL}$ ) was added and the resultant solution was stirred at $100^{\circ} \mathrm{C}$ for overnight. EtOAc was added to the mixture and unsoluble material was filtered through short silica column. The crude product was purified by column chromatography using hexane $/ \mathrm{CH}_{2} \mathrm{Cl}_{2}(10 / 1)$ solvent system. Yield: $48 \% .{ }^{1} \mathrm{H}$ NMR $\left(\mathrm{CDCl}_{3}, 400 \mathrm{MHz}\right): \delta_{H}(\mathrm{ppm}) 8.08-8.04$ (2H, d, Ar), 7.70-7.64 (2H, d, Ar), 7.58-7.46 (8H, m, Ar), 7.44-7.32 (12H, m, Ar), $1.42-1.36(18 \mathrm{H}, \mathrm{s}) .{ }^{13} \mathrm{C} \mathrm{NMR}\left(\mathrm{CDCl}_{3}, 100 \mathrm{MHz}\right): \delta_{C}(\mathrm{ppm}) 143.34$, $140.02,139.16,138.21,137.94,136.59,133.66,133.32,132.40$, $131.50,130.25,128.38,126.05,125.20,123.84,116.59,116.41$, 109.60, 34.97, 32.17.

\subsubsection{Synthesis of $\{4-[[4-(3,6-d i$-tert-butyl-9H-carbazole-9-yl)phenyl]} (diphenyl)silyl]phenyl\} boronic acid (4)

$50 \mathrm{~mL}$, 2-necked round-bottom flask was dried by using heat-gun. 9\{4-[(4-bromophenyl)(diphenyl)silyl]phenyl\}-3,6-di-tert-butyl-9H-carbazole $(2.90 \mathrm{mmol}, 2.00 \mathrm{~g})$ was added to the reaction flask. Three times vacum - gas (Ar) was applied to remove the $\mathrm{O}_{2}$ from the reaction flask. Dry THF $(30 \mathrm{~mL})$ was added to the reaction flask and the solution was cooled down to $-78^{\circ} \mathrm{C}$ by using dry ice/acetone mixture. After cooling, $n$-BuLi $(5.80 \mathrm{mmol}, 2.32 \mathrm{~mL})$ was added dropwise to the flask. The resultant solution was stirred at $-78{ }^{\circ} \mathrm{C}$ for $1 \mathrm{~h}$. After that, $\mathrm{B}(\mathrm{OMe})_{3}$ (11.6 mmol, $1.29 \mathrm{~mL}$ ) was added dropwise and the solution was left for stirring at RT for overnight. The reaction was stopped with the addition of $\mathrm{MeOH}(10-15 \mathrm{~mL})$ and solvents were evaporated on rotary evaporator. The crude product was purified by column chromatography using hexane/EtOAc (2/1) solvent system. Yield: $43 \%$. This product is directly used for the next step.

2.2.5. Synthesis of 3,6-di-tert-butyl-9-\{4-[[4-(4,6-dipheyl-1,3,5-triazine-2yl)phenyl](diphenyl) silyl] phenyl\}-9H-carbazole (tBuCz1SiTrz) (5)

$25 \mathrm{~mL}, 2$-necked round-bottom flask was dried by using heat-gun. \{4-[[4-(3,6-di-tert-butyl-9H-carbazole-9-yl)phenyl](diphenyl) silyl] phenyl\} boronic acid $(0.27 \mathrm{mmol}, 177.7 \mathrm{mg}), 2$-chloro-4,6-diphenyl1,3,5-triazine $\left(0.27 \mathrm{mmol}, 72.4 \mathrm{mg}\right.$ ) and $\mathrm{Cs}_{2} \mathrm{CO}_{3}(0.54 \mathrm{mmol}, 176.0 \mathrm{mg})$ were added to the reaction flask. Three times vacum - gas (Ar) was applied to remove the $\mathrm{O}_{2}$ from the reaction flask.1,4-dioxane $(5 \mathrm{~mL})$ was added to the flask and Argon gas was bubbled through the solution for about $30 \mathrm{~min} . \mathrm{Pd}\left(\mathrm{PPh}_{3}\right)_{4}(0.027 \mathrm{mmol}, 31.3 \mathrm{mg})$ was added to the flask and the resultant mixture was stirred at $100^{\circ} \mathrm{C}$ for overnight. 1,4dioxane was removed by using rotary evaporator and the crude product was purified by column chromatography using hexane $/ \mathrm{CH}_{2} \mathrm{Cl}_{2}(10 / 1)$ solvent system. Yield: $40 \% .{ }^{1} \mathrm{H}$ NMR $\left(\mathrm{CDCl}_{3}, 400 \mathrm{MHz}\right): \delta_{H}(\mathrm{ppm})$ 8.85-8.79 (6H, m, Ar), $8.17(2 \mathrm{H}, \mathrm{s}, \mathrm{Ar}), 7.92-7.89(2 \mathrm{H}, \mathrm{d}, J=8.0 \mathrm{~Hz}$, Ar), 7.87-7.85 (2H, d, $J=8.0 \mathrm{~Hz}, \mathrm{Ar}), 7.75-7.72(4 \mathrm{H}, \mathrm{d}, J=6.0 \mathrm{~Hz}$, Ar), 7.67-7.57 (9H, m, Ar), 7.53-7.47 (9H, m, Ar), 1.50 (s, $18 \mathrm{H}) .{ }^{13} \mathrm{C}$ $\mathrm{NMR}\left(\mathrm{CDCl}_{3}, 100 \mathrm{MHz}\right): \delta_{C}(\mathrm{ppm}) 171.74,143.06,139.75,139.60$, $138.95,137.80,137.53,136.76,136.45,136.20,133.56,132.54$, $132.35,129.97,128.98,128.63,128.18,128.14,125.83,123.61$, 123.58, 116.24,109.38, 34.74, 32.01, 29.70. MALDI-TOF MS, Found: $[\mathrm{M}]^{+}$m/z: 845.2498; 'molecular formula $\mathrm{C}_{59} \mathrm{H}_{52} \mathrm{~N}_{4} \mathrm{Si}^{\prime}$ requires $[\mathrm{M}]^{+}$ 845.1586 .

\subsubsection{Synthesis of 3,6-di-tert-butyl-9-(4-\{diphenyl[4-(tributylstannyl) phenyl] silyl\}phenyl)-9H-carbazole (6)}

$250 \mathrm{~mL}, 2$-necked round-bottom flask was dried by using heat-gun. 9-\{4-[(4-bromophenyl)(diphenyl)silyl]phenyl\}-3,6-di-tert-butyl-9H-carbazole $(6.64 \mathrm{mmol}, 4.60 \mathrm{~g})$ was added to the reaction flask. Three times vacum - gas (Ar) was applied to remove the $\mathrm{O}_{2}$ from the reaction flask. Dry THF $(100 \mathrm{~mL})$ was added to the reaction flask and the solution was cooled down to $-78^{\circ} \mathrm{C}$ by using dry ice/acetone mixture. After cooling, $n$-BuLi $(8.0 \mathrm{mmol}, 3.2 \mathrm{~mL})$ was added dropwise to the flask. The 
resultant solution was stirred at $-78^{\circ} \mathrm{C}$ for $1 \mathrm{~h}$. After that, $\mathrm{Bu}_{3} \mathrm{SnCl}$ ( $9.3 \mathrm{mmol}, 2.53 \mathrm{~mL})$ was added dropwise and the solution was left for stirring at RT for overnight. The reaction was stopped with the addition of $\mathrm{H}_{2} \mathrm{O}(100 \mathrm{~mL})$ and EtOAc $(100 \mathrm{~mL})$ was added. Organic phase was extracted and water phase was washed with $2 \times 50 \mathrm{~mL}$ EtOAc. Organic phases were combined and dried over $\mathrm{MgSO}_{4}$. Solvents were evaporated on rotary evaporator. The crude product was purified by column chromatography using cyclohexane $/ \mathrm{CH}_{2} \mathrm{Cl}_{2}$ (10/1) solvent system. Yield: $50 \% .{ }^{1} \mathrm{H} \mathrm{NMR}\left(\mathrm{CDCl}_{3}, 400 \mathrm{MHz}\right): \delta_{H}(\mathrm{ppm}) 8.18(2 \mathrm{H}, \mathrm{s}, \mathrm{Ar})$, 7.84-7.82 (2H, d, $J=8.0 \mathrm{~Hz}, \mathrm{Ar}), 7.71-7.69(4 \mathrm{H}, \mathrm{d}, J=8.0 \mathrm{~Hz}, \mathrm{Ar})$, 7.64-7.62 (4H, m, Ar), 7.59-7.57 (2H, d, $J=8.0 \mathrm{~Hz}, \mathrm{Ar}), 7.54-7.45$ (10H, m, Ar), 1.64-1.57 (16H, m), $1.51(18 \mathrm{H}, \mathrm{s}), 1.42-1.35(6 \mathrm{H}, \mathrm{m})$, 1.14-1.10 (6H, m), 0.96-0.93 (9H, t). ${ }^{13} \mathrm{C}$ NMR $\left(\mathrm{CDCl}_{3}, 100 \mathrm{MHz}\right): \delta_{C}$ (ppm) 144.51, 142.98, 139.45, 138.96, 137.82, 136.48, 136.14, 135.65 , 134.16, 129.75, 128.00, 125.70, 123.60, 123.51, 116.25, 109.40, 34.77, 32.05, 29.15, 27.45, 13.74, 9.62.

\subsubsection{Synthesis of 2,4-dichloro-6-phenyl-1,3,5-triazine (7)}

$250 \mathrm{~mL}$ 2-necked round-bottom flask was dried by using heat-gun. 2,4,6-trichloro-1,3,5-triazine ( $36 \mathrm{mmol}, 6.64 \mathrm{~g}$ ) was added to the reaction flask. Three times vacum - gas (Ar) was applied to remove the $\mathrm{O}_{2}$ from the reaction flask. Dry toluene $(60 \mathrm{~mL})$ was added to the reaction flask and the solution was cooled down to $0{ }^{\circ} \mathrm{C}$ by using ice/water bath. Phenylmagnesium bromide ( $\mathrm{PhMgBr}, 3 \mathrm{M} / \mathrm{Et}_{2} \mathrm{O}, 30 \mathrm{mmol}, 4.81 \mathrm{~mL}$ ) was added dropwise and the solution was left for stirring at RT for overnight. The reaction was stopped with the addition of water $(60 \mathrm{~mL})$ and organic phase was separated. Water phase was washed with $\mathrm{CH}_{2} \mathrm{Cl}_{2}$ $(60 \mathrm{~mL})$, organic phase were separated and dried over $\mathrm{MgSO}_{4}$. Solvents were evaporated on rotary evaporator and the crude product was purified by crystallization from hexzane $/ \mathrm{CH}_{2} \mathrm{Cl}_{2}$ solvent system. Yield: $65 \% .{ }^{1} \mathrm{H}$ NMR $\left(\mathrm{CDCl}_{3}, 400 \mathrm{MHz}\right): \delta_{H}(\mathrm{ppm})$ 8.55-8.52 $(2 \mathrm{H}, \mathrm{d}$, $J=8.0 \mathrm{~Hz}, \mathrm{Ar}) ; 7.70-7.67$ (1H, t, Ar); 7.58-7.55 (2H, t, Ar).

2.2.8. Synthesis of 9,9'-\{(6-phenyl-1,3,5-triazine-2,4-diyl)bis[4,1phenylene (diphenylsilanediyl)-4,1-phenylene]\}bis(3,6-di-tert-butyl-9Hcarbazole) (tBuCz2SiTrz) (8)

$50 \mathrm{~mL}, 2$-necked round-bottom flask was dried by using heat-gun. 3,6-di-tert-butyl-9-(4-\{diphenyl[4-(tributylstannyl)phenyl]silyl\}

phenyl)-9H-carbazole ( $1 \mathrm{mmol}, 0.90 \mathrm{~g}$ ) and 2,4-dichloro-6-phenyl1,3,5-triazine $(0.45 \mathrm{mmol}, 0.10 \mathrm{~g})$ were added to the reaction flask. Three times vacum - gas (Ar) was applied to remove the $\mathrm{O}_{2}$ from the reaction flask. Toluene $(20 \mathrm{~mL})$ was added to the flask and Argon gas was bubbled through the solution for about $30 \mathrm{~min}$. $\mathrm{Pd}\left(\mathrm{PPh}_{3}\right)_{4}$ $(0.10 \mathrm{mmol}, 0.12 \mathrm{~g})$ was added to the flask and the resultant mixture was stirred at $110^{\circ} \mathrm{C}$ for overnight. Toluene was removed by using rotary evaporator and the crude product was purified by column chromatography using hexane $/ \mathrm{CH}_{2} \mathrm{Cl}_{2}(5 / 1)$ solvent system. Yield: 20\%. ${ }^{1} \mathrm{H}$ NMR $\left(\mathrm{CDCl}_{3}, 400 \mathrm{MHz}\right): \delta_{H}(\mathrm{ppm}) \quad 8.62-8.58(4 \mathrm{H}, \mathrm{d}$, $J=8.4 \mathrm{~Hz}, \mathrm{Ar}$ ), 8.15 (4H, s, Ar), 7.85-7.77 (8H, m, Ar), 7.71-7.67 (8H, $\mathrm{m}, \mathrm{Ar}), 7.65-7.59$ (5H, m, Ar), 7.54-7.42 (24H, m, Ar), 1.48 (36H, s). ${ }^{13} \mathrm{C} \mathrm{NMR}\left(\mathrm{CDCl}_{3}, 100 \mathrm{MHz}\right): \delta_{C}(\mathrm{ppm}) 174.23,174.13,171.82,153.71$, $143.06,143.05,140.37,139.77,139.71,138.94,138.91,137.76$, $136.70,136.52,136.41,135.26,133.85,133.40,133.01,132.54$, $132.15,131.54,129.99,129.92,129.16,128.64,128.31,128.14$, 128.09, 125.81, 123.60, 123.57, 121.48, 116.23, 109.36, 34.73, 32.00, 29.71. MALDI-TOF MS, Found: $[\mathrm{M}+2 \mathrm{H}]^{+} \mathrm{m} / z$ : 1382.8058 ; 'molecular formula $\mathrm{C}_{97} \mathrm{H}_{89} \mathrm{~N}_{5} \mathrm{Si}_{2}{ }^{\prime}$ requires $[\mathrm{M}+2 \mathrm{H}]^{+} 1382.9685$.

2.2.9. Synthesis of 9,9',9"-\{1,3,5-triazine-2,4,6-triyl-tris[biphenyl-4',4-diyl (diphenylsilanediyl)-4,1-phenylene]\}tris(3,6-di-tert-butyl-9H-carbazole) (tBuCz3SiTrz) (9)

$50 \mathrm{~mL}, 2$-necked round-bottom flask was dried by using heat-gun. 3,6-di-tert-butyl-9-(4-\{diphenyl[4-(tributylstannyl)phenyl]silyl\}

phenyl)-9H-carbazole $(2.21 \mathrm{mmol}, 2.00 \mathrm{~g}$ ) and 2,4,6-trichloro-1,3,5triazine $(0.70 \mathrm{mmol}, 0.13 \mathrm{~g})$ were added to the reaction flask. Three times vacum - gas (Ar) was applied to remove the $\mathrm{O}_{2}$ from the reaction flask. Toluene $(20 \mathrm{~mL})$ was added to the flask and Argon gas was bubbled through the solution for about $30 \mathrm{~min} . \mathrm{Pd}\left(\mathrm{PPh}_{3}\right)_{4}(0.22 \mathrm{mmol}$, $0.26 \mathrm{~g}$ ) was added to the flask and the resultant mixture was stirred at $110^{\circ} \mathrm{C}$ for overnight. Toluene was removed by using rotary evaporator and the crude product was purified by column chromatography using hexane $/ \mathrm{CH}_{2} \mathrm{Cl}_{2}(5 / 1)$ solvent system. Yield: $23 \%$. ${ }^{1} \mathrm{H}$ NMR $\left(\mathrm{CDCl}_{3}\right.$, $400 \mathrm{MHz}): \delta_{H}(\mathrm{ppm}) 8.86-8.85(6 \mathrm{H}, \mathrm{d}, J=8.0 \mathrm{~Hz}, \mathrm{Ar}), 8.18$ (6H, s, Ar), $7.92-7.90(6 \mathrm{H}, \mathrm{d}, J=8.0 \mathrm{~Hz}, \mathrm{Ar}), 7.87-7.85(6 \mathrm{H}, \mathrm{d}, J=8.0 \mathrm{~Hz}, \mathrm{Ar})$, 7.75-7.73 (12H, d, $J=8.0 \mathrm{~Hz}, \mathrm{Ar}), 7.67-7.65(6 \mathrm{H}, \mathrm{d}, J=8.4 \mathrm{~Hz}, \mathrm{Ar})$, 7.57-7.48 (30H, m), $1.50(54 \mathrm{H}, \mathrm{s}) .{ }^{13} \mathrm{C} \mathrm{NMR}\left(\mathrm{CDCl}_{3}, 100 \mathrm{MHz}\right): \delta_{C}$ (ppm) 171.93, 143.06, 139.82, 139.76, 138.95, 137.80, 137.39, 136.79 , 136.45, 133.53, 132.30, 129.99, 128.15, 125.84, 123.61, 123.59, 116.24, 109.37, 34.74, 32.02. MALDI-TOF MS, Found: $[\mathrm{M}]^{+}$ m/z: 1916.7589; 'molecular formula $\mathrm{C}_{135} \mathrm{H}_{126} \mathrm{~N}_{6} \mathrm{Si}_{3}{ }^{\prime}$ requires $[\mathrm{M}]^{+}$ 1916.7465 .

\subsection{Preparation of hole and electron only devices}

Prior to organic layer deposition, the ITO substrates were cleaned with acetone, isopropanol under ultrasonic for $15 \mathrm{~min}$ and subjected to oxygen plasma treatment for $5 \mathrm{~min}$. PEDOT:PSS (Al4083) was spin coated at $2500 \mathrm{rpm}$ and the layer was annealed in a vacuum oven at $120^{\circ} \mathrm{C}$ for $30 \mathrm{~min}$. Following this, the molecules were dissolved in toluene at a total concentration of $10 \mathrm{mg} \mathrm{mL}^{-1}$ and were spin-coated onto the PEDOT:PSS layer and baked at $100^{\circ} \mathrm{C}$ for $30 \mathrm{~min}$. Finally, for the hole only devices, Au $(100 \mathrm{~nm})$ was deposited by thermal evaporation under a vacuum of $1 \times 10^{-6} \mathrm{mbar}$. The active areas of the devices were $4 \mathrm{~mm}^{2}$. For the electron only devices, ITO and Au layers of the above given device is replaced with $\mathrm{Al}$ layer of $100 \mathrm{~nm}$.

\section{Results and discussion}

\subsection{Synthesis}

The synthetic route followed for the bipolar host materials is shown in Fig. 1. 9H-carbazole was alkylated by using the Friedel-Crafts alkylation method and 3,6-di-tert-butyl-9H-carbazole (1) was obtained. Bis (4-bromophenyl)(diphenyl) silane (2) was synthesized by Li-halogen exchange reaction. The Ullmann Coupling reaction of 3,6-di-tert-butyl$9 \mathrm{H}$-carbazole with molecule 2 allowed to obtain molecule 3 . This $-\mathrm{Br}$ derivative was converted to boronic acid derivative (4) and used for the synthesis of bipolar host tBuCz1SiTrz (5) with Suzuki Coupling reaction.

Molecule 3 was also converted to tributyl stannyl (6) derivative. 2,4,6-trichloro-1,3,5-triazine and 2-chloro-4,6-diphenyl-1,3,5-triazine were purchased and 2,4-dichloro-6-phenyl-1,3,5-triazine (7) was synthesized. tBuCz2SiTrz (8) and tBuCz3SiTrz (9) were prepared through Stille Coupling reactions. The synthesized molecules were characterized by ${ }^{1} \mathrm{H}$ and ${ }^{13} \mathrm{C}$ NMR spectroscopy. Details of the structural characterizations are provided at Fig. S1a-h. The ratios of aromatic resonance peaks of tBuCz1-3SiTrz in the ${ }^{1} \mathrm{H}$ NMR spectra prove the presence of carbazole, triazine and phenyl units. The singlet signal at $1.50 \mathrm{ppm}$ indicates the presence of the methyl substituents on phenyl units. In the ${ }^{13} \mathrm{C}$ NMR spectra of tBuCz1-3SiTrz, the characteristic signals of the carbon atoms of the triazine units are observed at 171.7-174.2 ppm [20]. The formation of tBuCz1-3SiTrz were further supported by MALDI-TOF spectra (Fig. S2a-c).

\subsection{Photophysical properties}

The UV-Vis absorption and photoluminescence (PL) properties of the compounds were studied in cyclohexane $(\mathrm{CH})$, toluene, $\mathrm{CHCl}_{3}$ and THF (Fig. 2). The characteristic absorption peak at around $298 \mathrm{~nm}$ is identical for all compounds and assigned to the $\pi-\pi^{*}$ transition of the carbazole moieties. The longer wavelength ranging from $310 \mathrm{~nm}$ to $360 \mathrm{~nm}$ generates from the $\pi-\pi^{*}$ transition of the entire conjugated 


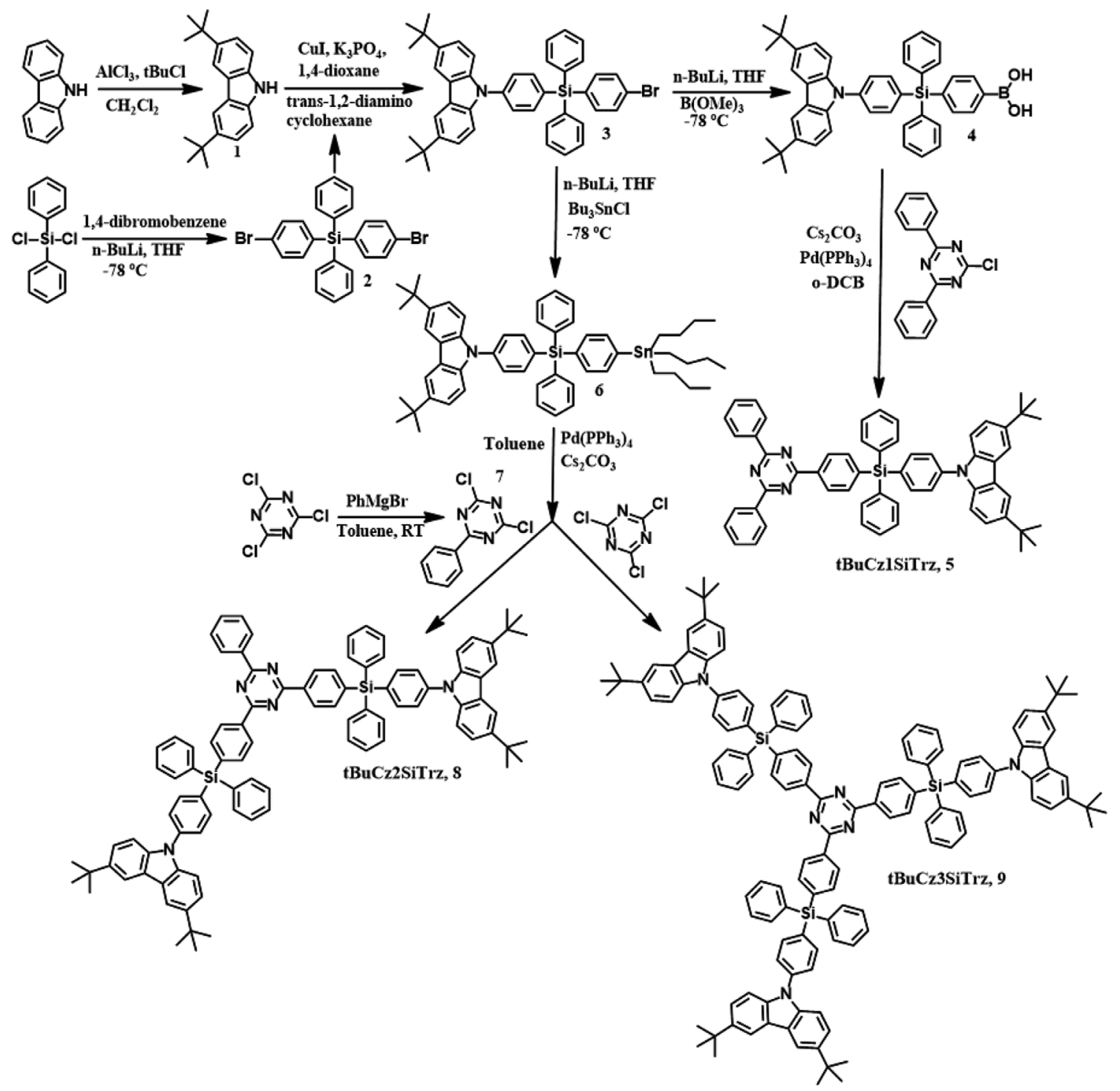

Fig. 1. Synthetic route for the synthesized molecules.

backbone. The intensity of $298 \mathrm{~nm}$ band increased with the increasing number of carbazole units and so did the calculated molar absorption constants $(\varepsilon)$ in toluene; the $\varepsilon$ values are in the range of $6.2 \times 10^{4}$ to $13.7 \times 10^{4} \mathrm{~L} / \mathrm{mol} . \mathrm{cm}$. All materials presented characteristic PL bands of non-conjugated carbazole group at $c a .354 \mathrm{~nm}$ and $370 \mathrm{~nm}$ [28]. In CH, well-structured locally exited (LE) state emission coming from the carbazole group is observed [29]. However, as the polarity of solvent was increased, gradual loss of the resolved fluorescence band, which is followed by appearance of unstructured and red-shifted Gaussian shaped emission originating from a newly formed state. This behaviour is attributed to formation ICT state between D and A groups [30,31].

In principle, as a result of photoexcitation, the LE state undergoes ICT from D to A (or vice versa) which is often accompanied by structural changes (i.e., relative folding of the $\mathrm{D}^{\delta+}$ and $\mathrm{A}^{\delta-}$ moieties) to form a new stabilized dipolar ICT state [30]. Structurally, if the linkage between the decoupled moieties is a formally single bond, the spatial folding between $\mathrm{D}^{\delta+}$ and $\mathrm{A}^{\delta-}$ moieties is precluded due to having a very limited degree of freedom in space, therefore, the internal rotational relaxations around the central bond are promoted and $\mathrm{D}^{\delta+}$ moiety takes an out of plane positions with respect to the $\mathrm{A}^{\delta-}$ moiety, which significantly change the electron density distribution to form a relaxed excited state. If the twist angle is around $90^{\circ}$ between the corresponding (aromatic) molecular moieties, the stabilization of charge transfer process significantly enhanced due to large amplitude torsional motion between $\mathrm{D}^{\delta+}$ to $\mathrm{A}^{\delta-}$ units. In such an orthogonal conformation, the electronic coupling is significantly favoured due to the reduced (nearly zero) overlap between the orbitals involved, and concomitantly intramolecular charge transfer state is formed between LE states. The prominent property of ICT state is to observe dual fluorescence, arising from LE and ICT states [32]. However, it must be noted that observation of dual fluorescence strongly depends on the competitions between radiative and non-radiative decay processes involved in different polarity/viscosity solvents [30,33]. Therefore, it is likely to see a broadened emission in polar solvents, arising from highly polarized ICT state. In all the molecules, the HOMO is localized onto the carbazole moiety, and the LUMO is confined to the triazine and the adjacent phenyl ring (Fig. 3). When electron-hole transport takes place between HOMO and LUMO orbitals, the charge carriers follow spatially separated pathways even when they happen to meet on one molecule (Fig. S3). Considering this point, the calculated emissive excited states involve mainly the transition from the carbazole-based HOMO to a triazine based LUMO, which have strong CT character (it carries no oscillator strength). The next emissive higher energy excited state $\left({ }^{1} \mathrm{LE}\right)$ is calculated to be $\sim 0.20 \mathrm{eV}$ above the ${ }^{1} \mathrm{CT}$ state and has oscillator strength for tBuCz1SiTrz (0.77), tBuCz2SiTrz (1.05) and tBuCz3SiTrz (1.28) (Table S1). We further consider that the broad and red-shifted 

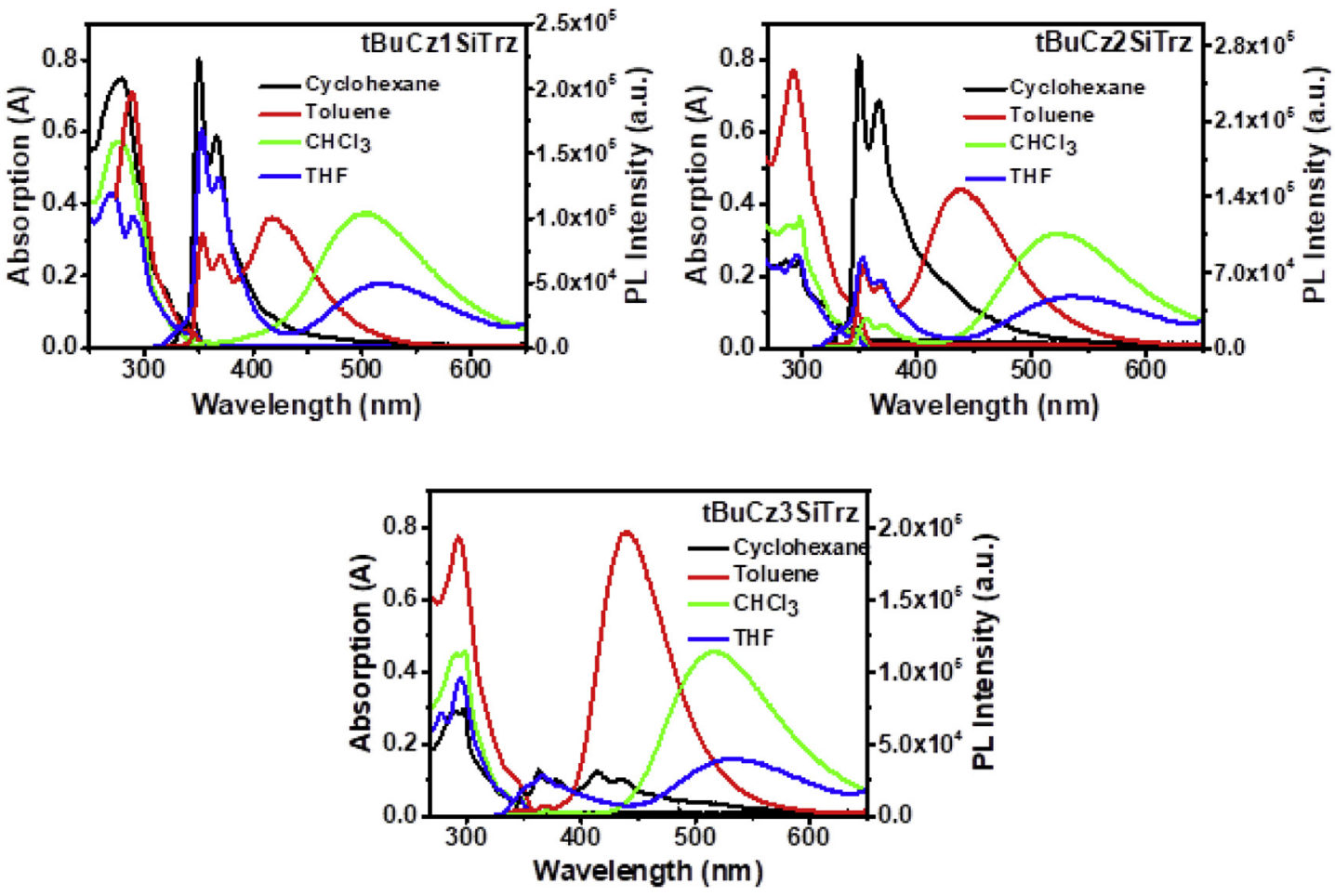

Fig. 2. UV-Vis absorbance and PL spectra of the molecules $\left(c=10^{-6} \mathrm{M}\right)$.

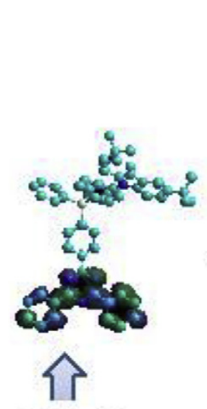

$3.87 \mathrm{eV}$
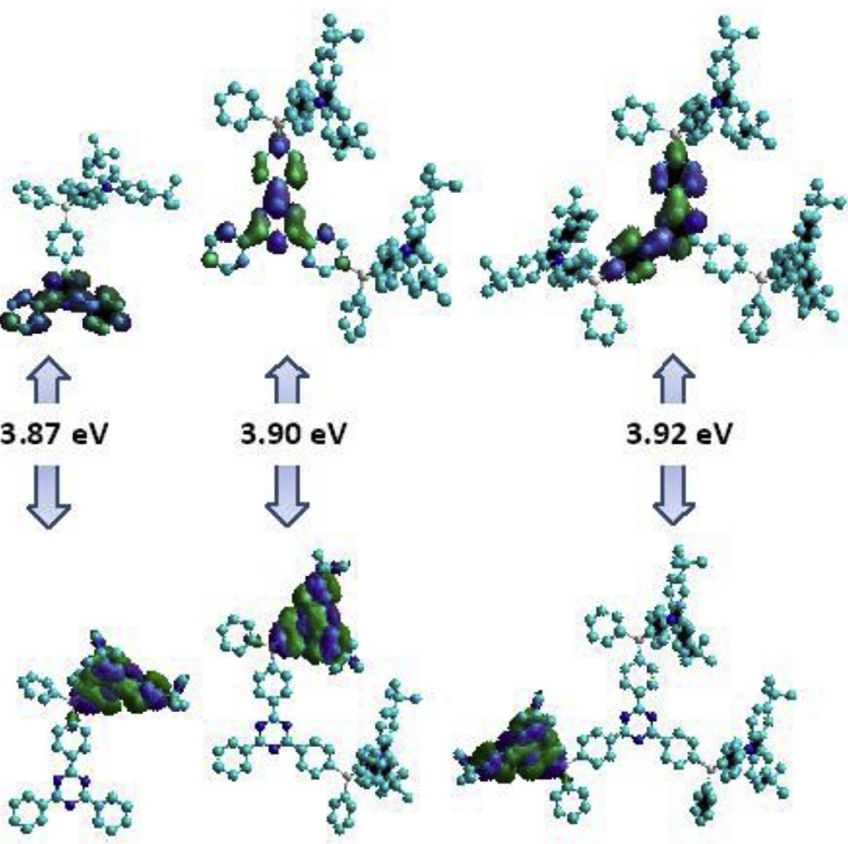

$3.90 \mathrm{eV}$
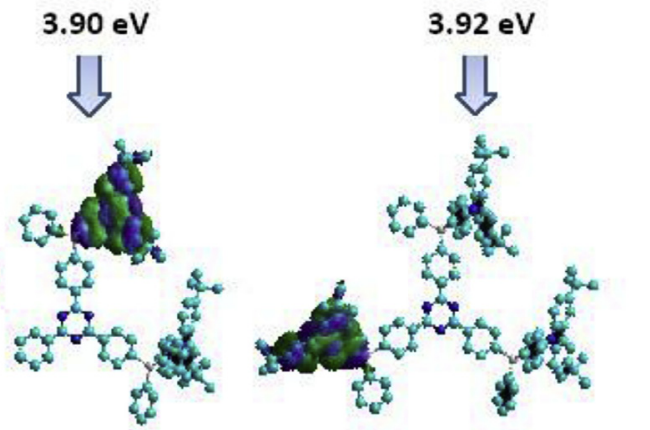

tBuCz1SiTrz

tBuCz2SiTrz

tBuCz3SiTrz

Fig. 3. Calculated localization of boundary molecular orbitals (HOMO and LUMO, semiempirical method AM1) participated in formation of the lowest singlet excited states of the tBuCz1-3SiTrz compounds. HOMO-LUMO energy gaps are given in $\mathrm{eV}$.

fluorescence arises from this ${ }^{1} \mathrm{CT}$ state due to the geometric relaxation in the excited state and concomitant planarization gives rise to slightly enhanced wave function overlap.

That is the case in here, in $\mathrm{CH}$, only one fluorescence band appears in all the molecules, as the viscosity and polarity are not sufficient to stabilize this twisted configuration [32]. However, once the polarity of solvent was slightly increased, it results in stabilization of an ICT state and concomitantly a further long-wavelength emission band grows in relative intensity (compared to LE emission), while the intensity of structured LE emission decreases with increasing solvent polarity (Fig. 2). In $\mathrm{CHCl}_{3}$, the emission from ${ }^{1} \mathrm{LE}$ state was totally vanished and the observation of red-shifted and broadened fluorescence are the indicatives of further relaxation of the excited-state geometric distortion and enhanced charge transfer strength. In general, the strength of an ICT state can be associated with solvatochromic shifts of the materials, and typically the largest positive solvatochromic shift is an indicative of the strongest ICT character. According to the findings [32], the molecules showing strong ICT character have reduced PLQY values, where monomolecular recombination of the geminately bound electron-hole pairs results in active radiative decay channels. Addressing this point, we measured the PL and PLQY values in toluene solution and drop casted films (Fig. 4), where the PLQY values in toluene were $47.2 \%$, $75.7 \%, 59.4 \%$ and in films were $8.2 \%, \% 36.4 \%$, \% 9.7\% for tBuCz1SiTrz, tBuCz2SiTrz, and tBuCz3SiTrz, respectively. Structurally, if the electron coupling between D-A units is strong (dihedral angle is close to $0^{\circ}$ ), the CT character of the state is weak. Indeed, the orientations of DA units play significant role on determining the singlet-triplet splitting energies $\left(\Delta \mathrm{E}_{\mathrm{S}-\mathrm{T}}\right)$ with the molecules having planar geometry show very large $\Delta \mathrm{E}_{\text {S-T }}$ value $(>0.7 \mathrm{eV})$, however, the $\Delta \mathrm{E}_{\mathrm{S}-\mathrm{T}}$ is significantly decreased $(<0.01 \mathrm{eV})$ with the molecules having $>80^{\circ}$ dihedral angle [34]. The results indicate that tBuCz2SiTrz molecule has the weakest ICT character (considering relatively narrow solvatochromic shift), localized energetically below the LE state which presumably results from reduced dihedral angle $\left(118^{\circ}\right.$ Fig. S4), comparing with tBuCz1SiTrz $\left(133^{\circ}\right)$ and tBuCz3SiTrz $\left(125^{\circ}\right)$. This conformational difference gives rise to increased PLQY values in tBuCz2SiTrz.

The fluorescence lifetimes were measured under varying conditions (air saturated and degassed) to understand the triplet contribution upon the fluorescence decays (Table 1). The molecules in toluene solution were excited at $298 \mathrm{~nm}$ and the emission from the ICT state was collected at $429 \mathrm{~nm}$ for tBuCz1SiTrz, $440 \mathrm{~nm}$ for tBuCz2SiTrz and $430 \mathrm{~nm}$ for tBuCz3SiTrz. The ICT emission of molecules shows triexponential decay components, one long lasting $\left(\tau_{3}\right)$ and two fast decays $\left(\tau_{1}\right.$ and $\left.\tau_{2}\right)$. 

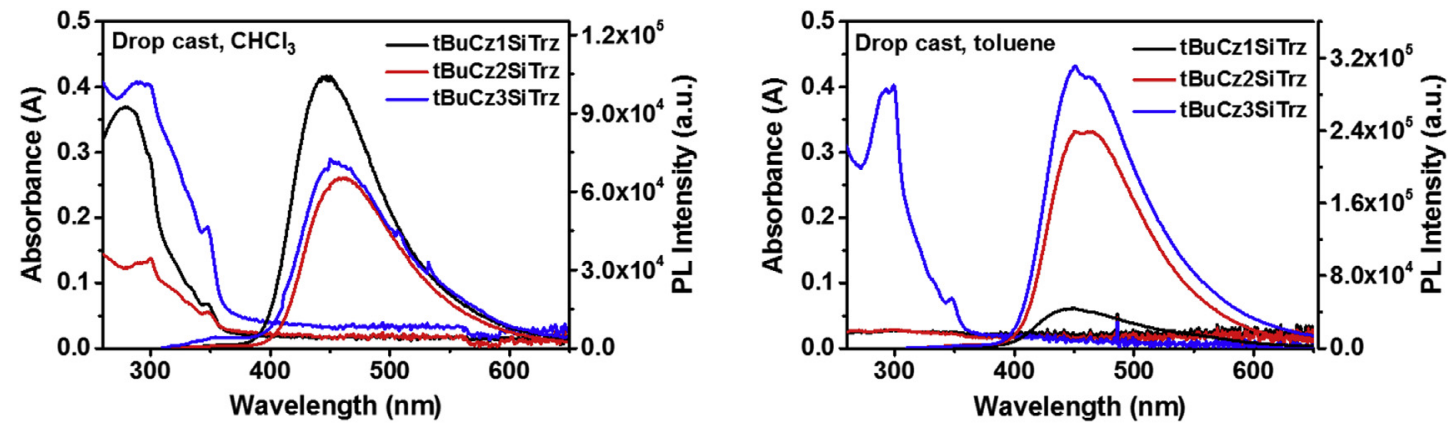

Fig. 4. UV-Vis absorbance and PL spectra of the drop casted films (prepared in $\mathrm{CHCl}_{3}$ and toluene, $\mathrm{c}=10^{-3} \mathrm{M}$ ).

Table 1

Fluorescence lifetime decays in toluene [air saturated (A-Saturated) and degassed] solution and drop cast films. In the table, $\tau$ represents lifetimes in nanosecond (ns) range, $\mathrm{B}$ and $f$ represent amplitudes of the components and fractional intensities (\%), respectively.

\begin{tabular}{|c|c|c|c|}
\hline Materials & $\begin{array}{l}\text { Solution } \\
\text { (A-saturated) }\end{array}$ & $\begin{array}{l}\text { Solution } \\
\text { (Degassed) }\end{array}$ & Drop-cast Film \\
\hline \multirow[t]{10}{*}{ tBuCz1SiTrz } & $B_{1}=72395.3$ & $B_{1}=11164.08$ & $B_{1}=4369.69$ \\
\hline & $f_{1}=48.87$ & $f_{1}=52.11$ & $f_{1}=10.20$ \\
\hline & $\tau_{1}=2.37 \mathrm{~ns}$ & $\tau_{1}=2.6 \mathrm{~ns}$ & $\tau_{1}=1.18 \mathrm{~ns}$ \\
\hline & $B_{2}=5433.7$ & $B_{2}=616.2$ & $B_{2}=17.649$ \\
\hline & $f_{2}=36.41$ & $f_{2}=20.72$ & $f_{2}=51.72$ \\
\hline & $\tau_{2}=2.37 \mathrm{~ns}$ & $\tau_{2}=18.7 \mathrm{~ns}$ & $\tau_{2}=14.79 \mathrm{~ns}$ \\
\hline & $B_{3}=385.8$ & $B_{3}=182.6$ & $B_{3}=306.54$ \\
\hline & $f_{3}=14.72$ & $f_{3}=27.18$ & $f_{3}=38.08$ \\
\hline & $\tau_{3}=13.51 \mathrm{~ns}$ & $\tau_{3}=82.82 \mathrm{~ns}$ & $\tau_{3}=62.69 \mathrm{~ns}$ \\
\hline & $\chi^{2}=1.26$ & $\chi^{2}=1.12$ & $\chi^{2}=1.12$ \\
\hline \multirow[t]{10}{*}{ tBuCz2SiTrz } & $B_{1}=11806.38$ & $B_{1}=10743.26$ & $B_{1}=13391.92$ \\
\hline & $f_{1}=66.43$ & $f_{1}=39.83$ & $f_{1}=6.37$ \\
\hline & $\tau_{1}=2.80 \mathrm{~ns}$ & $\tau_{1}=2.82 \mathrm{~ns}$ & $\tau_{1}=1.01 \mathrm{~ns}$ \\
\hline & $B_{2}=850.152$ & $B_{2}=660.45$ & $B_{2}=1213.68$ \\
\hline & $f_{2}=27.5$ & $f_{2}=15.15$ & $f_{2}=16.02$ \\
\hline & $\tau_{2}=16.12 \mathrm{~ns}$ & $\tau_{2}=17.46 \mathrm{~ns}$ & $\tau_{2}=27.9 \mathrm{~ns}$ \\
\hline & $B_{3}=26.92$ & $B_{3}=364.16$ & $B_{3}=1290.59$ \\
\hline & $f_{3}=6.07$ & $f_{3}=45.02$ & $f_{3}=77.6$ \\
\hline & $\tau_{3}=112.36 \mathrm{~ns}$ & $\tau_{3}=94.09 \mathrm{~ns}$ & $\tau_{3}=127.53 \mathrm{~ns}$ \\
\hline & $\chi^{2}=1.11$ & $\chi^{2}=1.09$ & $\chi^{2}=1.3$ \\
\hline \multirow[t]{10}{*}{ tBuCz3SiTrz } & $B_{1}=6737.77$ & $B_{1}=11280.26$ & $B_{1}=21655.61$ \\
\hline & $f_{1}=37.10$ & $f_{1}=44.54$ & $f_{1}=32.10$ \\
\hline & $\tau_{1}=2.55 \mathrm{~ns}$ & $\tau_{1}=2.54 \mathrm{~ns}$ & $\tau_{1}=0.54 \mathrm{~ns}$ \\
\hline & $B_{2}=5617.28$ & $B_{2}=932.88$ & $B_{2}=1283.23$ \\
\hline & $f_{2}=30.93$ & $f_{2}=50.07$ & $f_{2}=41.18$ \\
\hline & $\tau_{2}=2.55 \mathrm{~ns}$ & $\tau_{2}=2.54 \mathrm{~ns}$ & $\tau_{2}=11.66 \mathrm{~ns}$ \\
\hline & $B_{3}=872.57$ & $B_{3}=13.74$ & $B_{3}=136.93$ \\
\hline & $f_{3}=31.97$ & $f_{3}=5.39$ & $f_{3}=26.73$ \\
\hline & $\tau_{3}=16.96 \mathrm{~ns}$ & $\tau_{3}=252.94 \mathrm{~ns}$ & $\tau_{3}=70.91 \mathrm{~ns}$ \\
\hline & $\chi^{2}=1.35$ & $\chi^{2}=0.97$ & $\chi^{2}=1.24$ \\
\hline
\end{tabular}

The large lifetime differences between the components indicate that they are of different origin. One of the fast components $\left(\tau_{1}\right)$ can be attributed to ${ }^{1} \mathrm{LE}$ emission of molecules and $\tau_{2}$ may result from partially twisted geometry of the molecules giving rise to a fast non-radiative decay channel. The long lasting component $\left(\tau_{3}\right)$ shows strong oxygen dependency, where the lifetimes increase significantly in tBuCz1SiTrz and tBuCz3SiTrz materials. However, in tBuCz2SiTrz, the lifetime slightly decreases with oxygen (Table 1). The presumable reason is that, the energy of ICT state is $\sim 2.92 \mathrm{eV}$ for tBuCz2SiTrz molecule, which is lower than the energy of locally excited triplet state $\left({ }^{3} \mathrm{LE} \sim 2.98 \mathrm{eV}\right.$, Fig. S5) and therefore, the ICT state of tBuCz2SiTrz is energetically lowest state of the system. However, for the others, the lowest energy of the system is ${ }^{3} \mathrm{LE}$ state, where the ICT state of tBuCz1SiTrz and tBuCz3SiTrz localizes $\sim 0.12 \mathrm{eV}$ and $\sim 0.11 \mathrm{eV}$ above the energy of ${ }^{3} \mathrm{LE}$ state, respectively (Fig. 5). Consequentially, long-lasting components $\left(\tau_{3}\right)$ of the molecules indicates the lifetime of the ICT states, where the triplets make significant contribution by forming a feeding mechanism from ${ }^{3} \mathrm{LE}$ state of tBuCz1SiTrz and tBuCz3SiTrz molecules. However, in tBuCz2SiTrz molecule, the energy difference between ICT and ${ }^{3} \mathrm{LE}$ state is $\sim 0.06 \mathrm{eV}$, which is very close for active triplet feeding mechanism, therefore, the $\tau_{3}$ component has the longest lifetime even in air-saturated solution and drop-off slightly in degassed environment due to actively operative non-radiative decay channels of ${ }^{3} \mathrm{LE}$ state. Taken together, for all three molecules, excitation at $298 \mathrm{~nm}$ accesses the ${ }^{1} \mathrm{LE}$ state of carbazole, then in nanosecond range the ICT state is directly populated by both ${ }^{1} \mathrm{LE}$ and ${ }^{3} \mathrm{LE}$.

\subsection{Electrochemical studies}

The electrochemical behaviour of the synthesized molecules showed quasi reversible oxidation $\left(\mathrm{E}_{\mathrm{ox}}\right)$ at around $1.3 \mathrm{eV}$, irreversible reduction $\left(E_{\text {red1 }}\right)$ between -0.70 and $-0.48 \mathrm{eV}$ and reversible reduction $\left(E_{\text {red2 }}\right)$ between -1.30 and $-1.42 \mathrm{eV}$ (Fig. $6 \mathrm{a}$ and Table 2). $\mathrm{E}_{\mathrm{ox}}$ generates from the D whereas, $\mathrm{E}_{\mathrm{red} 1}$ are assigned to the ICT state and the $\mathrm{E}_{\mathrm{red} 2}$ belong to reduction of A [16,31]. The HOMO and LUMO energy levels of the molecules are calculated from the onset of $\mathrm{E}_{\mathrm{ox}}$ and $\mathrm{E}_{\mathrm{red} 2}$ and found to be around $-5.6 \mathrm{eV}$ and $-2.9 \mathrm{eV}$, respectively. Although the number of electron donating carbazole groups around the electron accepting triazine was increased, because of the interrupted conjugation, close running HOMO and LUMO energy levels were obtained. The electrochemical stabilities of the synthesized molecules were determined by consecutive cyclic measurements. Although no significant deviation was expected at the $\mathrm{E}_{\mathrm{ox}}$ of all molecules as the $\mathrm{C} 3$ and $\mathrm{C} 6$ positions of carbazoles were protected ${ }^{20}$, only tBuCz2SiTrz ensured this expectation. tBuCz1SiTrz and tBuCz3SiTrz presented growing current peaks at higher oxidative potentials $(1.5 \mathrm{~V})$, pointing out that the electron density on the carbazole groups of these molecules were decreased. While the reduction of triazine was preserved, a current increase at ICT state reduction potential of all molecules was obtained. Growing of the currents suggests an electrochemically induced charge transfer with an

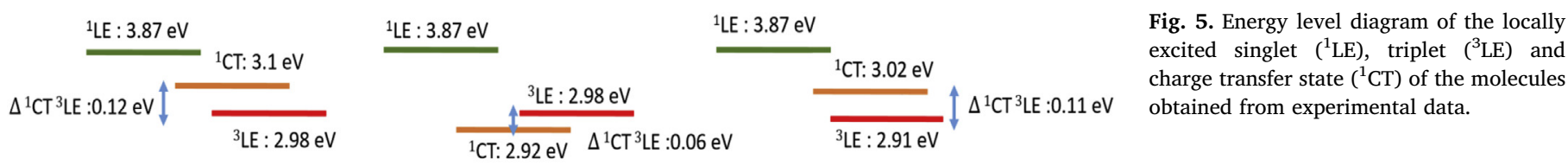



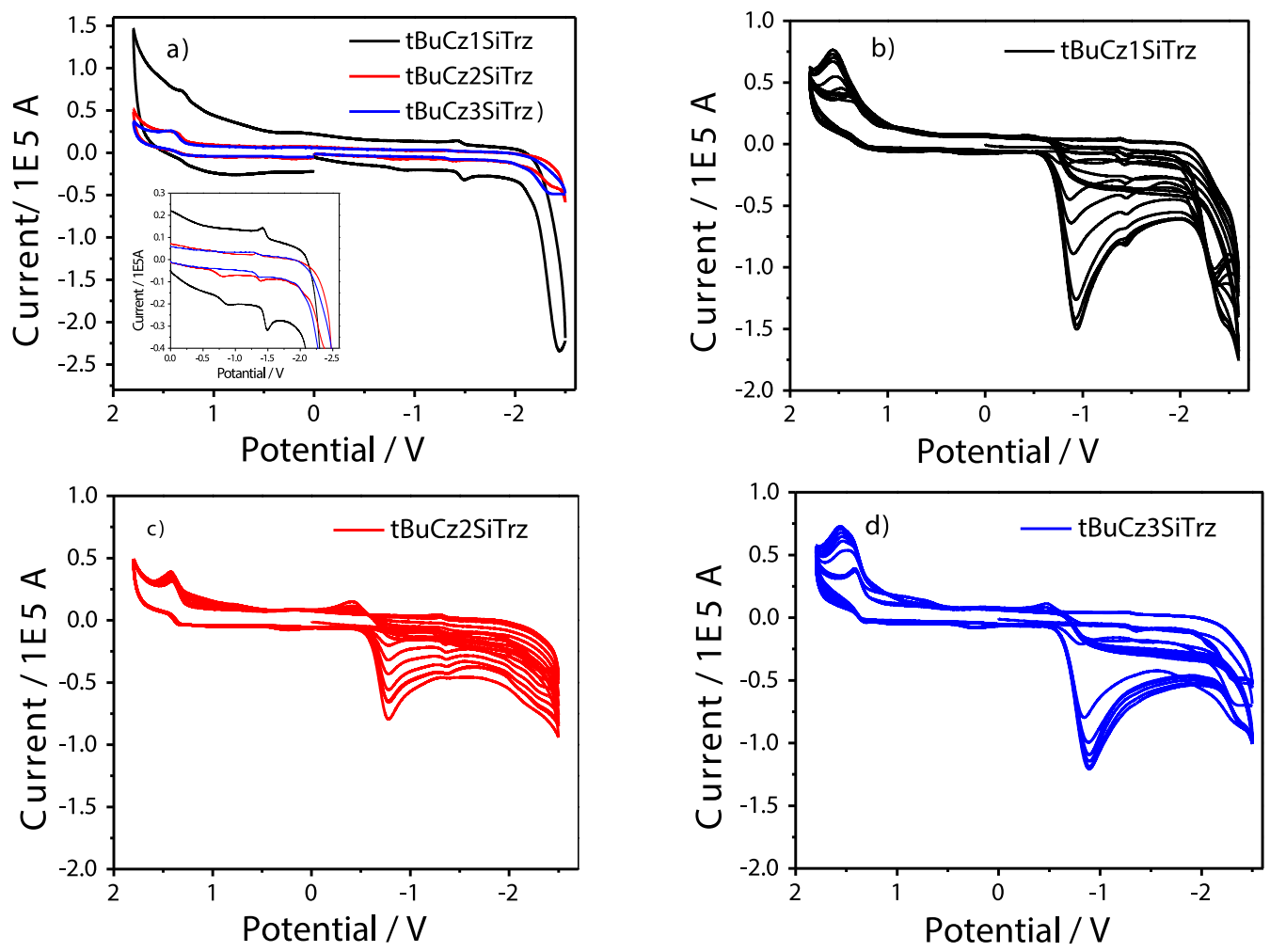

Fig. 6. a) Cyclic voltammograms of the synthesized molecules (inset: zoomed reduction area) and b-d) consecutive cyclic scanning of the molecules.

Table 2

Electrochemical data obtained by the cyclic measurements.

\begin{tabular}{llllll}
\hline Molecule & $\begin{array}{l}\mathrm{E}_{\text {ox }} \\
(\mathrm{V})\end{array}$ & $\begin{array}{l}\mathrm{E}_{\text {red1 }} \\
(\mathrm{V})\end{array}$ & $\begin{array}{l}\mathrm{E}_{\text {red2 }} \\
(\mathrm{V})\end{array}$ & $\begin{array}{l}\text { HOMO } \\
(\mathrm{eV})\end{array}$ & $\begin{array}{l}\text { LUMO } \\
(\mathrm{eV})\end{array}$ \\
\hline tBuCz1SiTrz & 1.26 & -0.70 & -1.42 & -5.59 & -2.91 \\
tBuCz2SiTrz & 1.27 & -0.61 & -1.34 & -5.55 & -2.94 \\
tBuCz3SiTrz & 1.28 & -0.48 & -1.30 & -5.56 & -2.98 \\
\hline
\end{tabular}

enhancement order of tBuCz2SiTrz $<$ tBuCz3SiTrz $<$ tBuCz1SiTrz (Fig. 6b-d). These growing currents corresponds to the potentials of $-0.92 \mathrm{~V},-0.78 \mathrm{~V}$ and $-0.89 \mathrm{~V}$ for the increasing order of carbazole units. Lowest charge transfer reduction potential and current enhancement obtained with tBuCz2SiTrz molecule, supports the discussions provided above on low laying ICT state of this molecule.

\subsection{Studies of hole and electron only devices}

In order to monitor the charge balance in the molecules, hole and

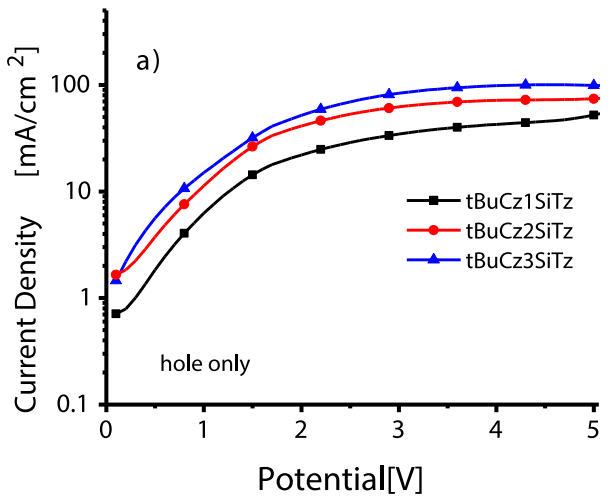

electron only devices with the structures of ITO/PEDOT:PSS ( $\approx 40 \mathrm{~nm}) /$ tBuCz1-3SiTrz $(\approx 60 \mathrm{~nm}) / \mathrm{Au}(100 \mathrm{~nm})$ and Al $(200 \mathrm{~nm}) / \mathrm{tBuCz} 1-3 \mathrm{SiTrz}$ $(\approx 60 \mathrm{~nm}) / \mathrm{Cs}_{2} \mathrm{CO}_{3}(3 \mathrm{~nm}) / \mathrm{Al}(200 \mathrm{~nm})$, respectively were prepared. The hole densities were increased with the increasing number of carbazole groups while the electron currents were decreased. For tBuCz3SiTrz molecule, the hole density of the device is higher than the electron density, the situation is the other way around for tBuCz1SiTrz molecule and for tBuCz2SiTrz, current density-voltage curves address a charge balance (Fig. 7).

\section{Conclusions}

In conclusion, three novel, bipolar materials were synthesized by increasing the number of electron donating (D) carbazole units around the electron accepting (A) triazine. The conjugation between the D and A was interrupted by tetraphenylsilane groups and high-triplet energy, solution-processable bipolar blue emitting materials were obtained. All presented solvatochromic shifts. Photophysical and electrochemical characterizations showed the potential of these molecules as blue

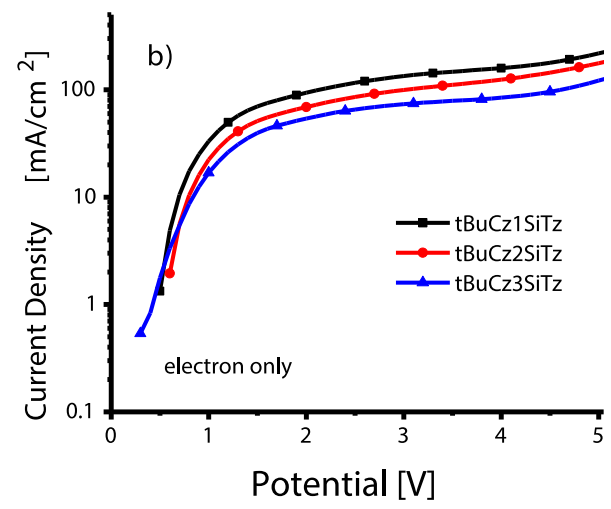

Fig. 7. Current density-Voltage curves of a) hole and b) electron only devices. 
emitters and bipolar host materials for green emitting OLED applications and that tBuCz2SiTrz has the weakest intramolecular charge transfer character, highest PLQY and charge balance.

\section{Acknowledgements}

The authors would like to thank Ilker Oner and Daniel Voltz for fruitful discussions, project support funds of TUBITAK (113Z253) and IYTE Biological Mass Spectrometry and Proteomic Laboratory.

\section{Appendix A. Supplementary data}

Supplementary data related to this article can be found at http://dx. doi.org/10.1016/j.dyepig.2018.06.014.

\section{References}

[1] Xiang C, Fu X, Wei W, Liu R, Zhang Y, Balema V, Nelson B, So F. Efficiency roll-off in blue emitting phosphorescent organic light emitting diodes with carbazole host materials. Adv Funct Mater 2016;26:1463-9.

[2] Nagai Y, Sasabe H, Ohisa S, Kido J. Effect of substituents in a series of carbazolebased host-materials toward high-efficiency carbene-based blue OLEDs. J Mater Chem C 2016;4:9476-81.

[3] Sun W, Zhou N, Xiao Y, Wang S, Li X. Novel carbazolyl-substituted spiro[acridine9,9'-fluorene] derivatives as deep-blue emitting materials for OLED applications. Dyes Pigments 2018;154:30-7.

[4] Gudeika D, Grazulevicius JV, Volyniuk D, Butkute R, Juska G, Miasojedovas A, Gruodis A, Jursenas S. Structure-properties relationship of the derivatives of carbazole and 1,8-naphthalimide: effects of the substitution and the linking topology. Dyes Pigments 2015;114:239-52.

[5] Konidena RK, Thomas KRJ, Kumar S, Wang Y-C, Li C-J, Jou J-H Phenothiazine decorated carbazoles: effect of substitution pattern on the optical and electroluminescent characteristics. J Org Chem 2015;80:5812-23.

[6] Hung W-Y, Chi L-C, Chen W-J, Chen Y-M, Chou S-H, Wong K-T. A new benzimidazole/carbazole hybrid bipolar material for highly efficient deep-blue electrofluorescence, yellow-green electrophosphorescence, and two-color-based white OLEDs. J Mater Chem 2010;20:10113-9.

[7] Thiery S, Tondelier D, Geffroy B, Jacques E, Robin M, Métivier R, Jeannin O, RaultBerthelot J, Poriel C. Spirobifluorene-2,7-dicarbazole-4'-phosphine oxide as host for high-performance single-layer green phosphorescent OLED devices. Org Lett 2015;17:4682-5.

[8] Palayangoda SS, Cai X, Adhikari RM, Neckers DC. Carbazole-based donor-acceptor compounds: highly fluorescent organic nanoparticles. Org Lett 2008;10:281-4.

[9] Zhang R, Sun H, Zhao Y, Tang X, Ni Z. Dipolar 1,3,6,8-tetrasubstituted pyrene-based blue emitters containing electro-transporting benzimidazole moieties: syntheses, structures, optical properties, electrochemistry and electroluminescence. Dyes Pigments 2018;152:1-13.

[10] Huixia X, Fanga W, Kexiang W, Yanqin M, Jie L, Jing Z, Hua W, Yuying H, Bingshe $\mathrm{X}$. Three acceptors based bipolar materials with tunable excited state natures and applications as non-doped blue emitters and hosts in OLEDs. Dyes Pigments 2018;155:84-92.

[11] Kim M, Jeon SK, Hwang S-H, Lee JY. Molecular design of triazine and carbazole based host materials for blue phosphorescent organic emitting diodes. Phys Chem Chem Phys 2015;17:13553-8.

[12] Sun Q, Cui L-S, Xie Y-M, Liang J-J, Jiang Z, Liao L, Fung M-K. Aminoborane-based bipolar host material for blue and white-emitting electrophosphorescence devices. Org Electron 2017;48:112-7.

[13] Jiang W, Duan L, Qiao J, Dong G, Wang L, Qiu Y. Tuning of charge balance in bipolar host materials for highly efficient solution-processed phosphorescent devices. Org Lett 2011;13:3146-9.
[14] Lin M-S, Chi L-C, Chang H-W, Huang Y-H, Tien K-C, Chen C-C, Chang C-H, Wu C-C, Chaskar A, Chou S-H, Ting H-C, Wong K-T, Liu Y-H, Chi Y. A diarylborane-substituted carbazole as a universal bipolar host material for highly efficient electrophosphorescence devices. J Mater Chem 2012;22:870-6.

[15] Hu M, Liu Y, Chen Y, Song W, Gao L, Mu H, Huang J, Su J. Highly efficient triazine/ carbazole-based host material for green phosphorescent organic light-emitting diodes with low efficiency roll-off. RSC Adv 2017;7:7287-92.

[16] Chang C-H, Kuo M-C, Lin W-C, Chen Y-T, Wong K-T, Chou S-H, Mondal E, Kwong RC, Xia S, Nakagawa T, Adachi C. A dicarbazole-triazine hybrid bipolar host material for highly efficient green phosphorescent OLEDs. J Mater Chem 2012;22:3832-8.

[17] Wagner D, Hoffmann ST, Heinemeyer U, Münster I, Köhler A, Strohriegl P. Triazine based bipolar host materials for blue phosphorescent OLEDs. Chem Mater 2013;25:3758-65.

[18] Rothmann MM, Fuchs E, Schildknecht C, Langer N, Lennartz C, Münster I, Strohriegl P. Designing a bipolar host material for blue phosphorescent OLEDs: phenoxy-carbazole substituted triazine. Org Electron 2011;12:1192-7.

[19] Chen D, Su S-J, Cao Y. Nitrogen heterocycle-containing materials for highly efficient phosphorescent OLEDs with low operating voltage. J Mater Chem C 2014;2:9565-78.

[20] Matulaitis T, Kostiv N, Grazulevicius JV, Peciulyte L, Simokaitiene J, Jankauskas V, Luszczynska B, Ulanski J. Synthesis and properties of bipolar derivatives of 1,3,5triazine and carbazole. Dyes Pigments 2016;127:45-58.

[21] Lu T, You J, Zhao D, Wang H, Miao Y, Liu X, Xiao Y, Li X, Wang SJ. Synthesis of novel s-triazine/carbazole based bipolar molecules and their application in phosphorescent OLEDs. Mater Sci Mater Electron 2015;26:6563-71.

[22] Grabowski ZR, Rotkiewicz K, Rettig W. Structural changes accompanying intramolecular electron transfer: focus on twisted intramolecular charge-transfer states and structures. Chem Rev 2003;103:3899-4032.

[23] Zhao Z-H, Jin H, Zhang Y-X, Shen Z, Zou D-C, Fan X-H. Synthesis and properties of dendritic emitters with a fluorinated starburst oxadiazole core and twisted carbazole dendrons. Macromolecules 2011;44:1405-13.

[24] Liu D, Du M, Chen D, Ye K, Zhang Z, Liu Y, Wang Y. A novel tetraphenylsilane-phenanthroimidazole hybrid host material for highly efficient blue fluorescent, green and red phosphorescent OLEDs. J Mater Chem C 2015;3:4394-401.

[25] Kang J-W, Lee D-S, Park H-D, Kim JW, Jeong W-I, Park Y-S, Lee S-H, Go K, Lee J-S, Kim J-J. A host material containing tetraphenylsilane for phosphorescent OLEDs with high efficiency and operational stability. Org Electron 2008;9:452-60.

[26] Sutton JJ, Barnsley JE, Mapley JI, Wagner P, David L, Officer DL, Gordon KC. Modulation of donor-acceptor distance in a series of carbazole push-pull dyes; a spectroscopic and computational study. Molecules 2018;23:421.

[27] Alyar HA. Review on nonlinear optical properties of donor-acceptor derivatives of naphthalene and azanaphthalene. Rev Adv Mater Sci 2013;34:79-87.

[28] Imae I, Kawakami YJ. Unique photoluminescence property of a novel perfectly carbazole-substituted POSS. Mater Chem 2005;15:4581-3.

[29] Li W, Liu D, Shen F, Ma D, Wang Z, Feng T, Xu Y, Yang B, Ma Y. A twisting donoracceptor molecule with an intercrossed excited state for highly efficient, deep-blue electroluminescence. Adv Funct Mater 2012;22:2797-803.

[30] Izguierdo MA, Bell TDM, Habuchi S, Fron E, Pilot R, Vosch T, Feyter SD, Verhoeven J, Jacop J, Müllen K, Hofkens J, Schryver FC. Chem Phys Lett 2005;401:503-8.

[31] Benniston AC, Harriman A, Li P, Rostron JP, van Ramesdonk HJ, Groeneveld MM, Zhang H, Verhoeven JW. J Am Chem Soc 2005;127:16054-64.

[32] Aydemir M, Haykir G, Turksoy F, Gumus S, Dias FB, Monkman AP. Synthesis and investigation of intra-molecular charge transfer state properties of novel donoracceptor-donor pyridine derivatives: the effects of temperature and environment on molecular configurations and the origin of delayed fluorescence. Phys Chem Chem Phys 2015;17:25572-82.

[33] Bangal PR, Panja S, Chakravorti SJ. Excited state photodynamics of 4-N,N-dimethylamino cinnamaldehyde:: a solvent dependent competition of TICT and intermolecular hydrogen bonding. Photochem Photobiol A Chem 2001;139:5-16.

[34] Dias FB, Santos J, Graves DR, Data P, Nobuyasu RS, Fox MA, Batsanov AS, Palmeira T, Berberan-Santos MN, Bryce MR, Monkman AP. The role of local triplet excited states and D-A relative orientation in thermally activated delayed fluorescence: photophysics and devices. Adv Sci 2016;3:1600080. 